\title{
PENGARUH PENDEKATAN BELAJAR TERHADAP KELULUSAN OSCE UKMPPD MAHASISWA FAKULTAS KEDOKTERAN DAN ILMU KESEHATAN UNIVERSITAS JAMBI
}

\author{
Amelia Dwi Fitri, Nyimas Natasha A Shafira \\ Bagian Pendidikan Kedokteran Fakultas Kedokteran dan IImu Kesehatan Universitas Jambi \\ e-mail: dwifitri.amelia@gmail.com
}

\begin{abstract}
Learning strategies or commonly known as learning approaches are the intentions and motivations of individuals and the use of appropriate strategies when dealing with the learning environment. In general, learning strategies can be divided into two categories, namely a deep approach and a surface approach. A deep approach is characterized by a desire to understand the material so as to produce good quality learning outcomes. A student who uses an in-depth approach has the intention to understand learning material and is motivated by an interest in learning material. Conversely, a surface approach is characterized by a desire to achieve minimal results with minimal effort resulting in low quality learning outcomes. The superficial approach is related to various forms of rote learning, with fear of failure as the dominant motivation. Therefore, the learning approach can influence learning outcomes. One of the learning outcomes assessed is the Objective Structured Clinical Examination (OSCE) Student Competency Test for Doctor Professional Programs (UKMPPD). The purpose of this study is to look at the effect of the learning strategies and OSCE UKMPPD graduation period of May 2018 and August 2018 in medical profession students of the Faculty of Medicine and Health Sciences University of Jambi (FKIK UNJA). The research method is descriptive analytic with cross-sectional approach. The population is FKIK UNJA medical profession students who participated in the OSCE UKMPPD for the period of May 2018 and August 2018 as many as 59 students. The sample is the entire population (total sampling). Student learning approach data obtained by using the questionnaire "Revised Study Process Questionnaire 2 Factors (R-SPQ-F2). UKMPPD OSCE graduation data is the official UKMPPD graduation data issued by the UKMPPD national committee. The test used to see the effect is a regression test, the most learning approach is deep approach $50.85 \% \%$ and obtained $p<0.05$, which indicates there is an influence between the learning strategies with OSCE UKMPPD graduation.
\end{abstract}

Keywords: OSCE, UKMPPD, Medical Student 


\section{ABSTRAK}

Strategi pembelajaran atau yang biasa dikenal sebagai pendekatan belajar merupakan intensi dan motivasi individu serta penggunaan strategi yang sesuai ketika menghadapi lingkungan pembelajaran. Secara umum, strategi pembelajaran dapat dibagi menjadi dua kategori yaitu pendekatan mendalam (deep approach) dan pendekatan dangkal (surface approach).Pendekatan mendalam ditandai dengan keinginan untuk memahami materi sehingga menghasilkan kualitas hasil belajar yang baik. Seorang mahasiswa yang menggunakan pendekatan mendalam memiliki niat untuk memahami materi pembelajaran dan dimotivasi oleh ketertarikan pada materi pembelajaran. Sebaliknya, pendekatan dangkal ditandai dengan keinginan untuk mencapai hasil minimal dengan usaha minimal sehingga menghasilkan kualitas hasil belajar yang rendah. Pendekatan dangkal terkait dengan berbagai bentuk pembelajaran hafalan, dengan rasa takut akan kegagalan sebagai motivasi dominan.Oleh karena itu, pendekatan belajar dapat mempengaruhi hasil belajar. Salah satu hasil belajar yang dinilai adalah Objective Structured Clinical Examination (OSCE) Uji Kompetensi Mahasiswa Program Profesi Dokter (UKMPPD). Tujuan penelitian ini adalah untuk melihat pengaruh pendekatan belajar dan kelulusan OSCE UKMPPD periode Mei 2018 dan Agustus 2018 mahasiswa profesi dokter Fakultas Kedokteran dan IImu Kesehatan Universitas Jambi (FKIK UNJA). Metode penelitian adalah deskriptif analitik dengan pendekatan cross-sectional. Populasi adalah mahasiswa profesi dokter FKIK UNJA yang mengikuti OSCE UKMPPD periode Mei 2018 dan Agustus 2018 sebanyak 59 orang. Sampel adalah seluruh populasi (total sampling). Data pendekatan belajar mahasiswa didapatkan dengan menggunakan kuesioner "Revised Study Process Questionnaire 2 Factors (R-SPQ-F2). Data kelulusan OSCE UKMPPD adalah data resmi kelulusan UKMPPD yang dikeluarkan oleh panitia nasional UKMPPD. Uji yang digunakan untuk melihat pengaruh adalah uji regresi, Pendekatan belajar yang terbanyak adalah $50.85 \% \%$ dan didapatkan $\mathrm{p}<$ 0,05, yang menandakan ada pengaruh antara pendekatan belajar dengan kelulusan OSCE UKMPPD.

\section{Kata Kunci :OSCE, UKMPPD, Mahasiswa Kedokteran}




\section{PENDAHULUAN}

Pendekatan belajar atau yang biasa disebut learning approach adalah cara seseorang dalam menyelesaikan dan mencapai tujuan pembelajaran. Pendekatan belajar pertama kali diperkenalkan oleh Malton dan Saljo pada tahun 1976. Pendekatan belajar terdiri dari dua pendekatan yaitu pendekatan mendalam (deep approach) dan dangkal (surface approach). ${ }^{1}$ Juga ada yang menambahkan dengan pendekatan yang berorientasi hasil (achieving). Pendekatan belajar yang diterapkan oleh mahasiswa dipengaruhi oleh motivasi mahasiswa dan lingkungan belajar. Pendekatan belajar bukan merupakan akteristik mahasiswa tetapi tergantung dari konteks pembelajaran. 1,2

Pendekatan belajar dapat mempengaruhi hasil belajar. Pendekatan belajar berhubungan positif dengan kualitas belajar. Jika pendekatan belajar dengan deep approach maka kualitas belajar juga baik tetapi jika pendekatan belajar dangkal atau surface maka kualitas belajar juga tidak baik. 1,2 Penelitian Lietz mendapatkan bahwa pendekatan belajar merupakan salah satu faktor dalam pencapaian hasil belajar mahasiswa. Mahasiswa belajar dengan pendekatan belajar dangkal atau surface maka hasil belajarnya akan rendah. Sedangkan mahasiswa belajar dengan pendekatan deep approach akan mendapatkan hasil yang lebih baik. Penelitian Tarabashkina menunjukan bahwa pendekatan belajar berhubungan positif dengan perfoma mahasiswa. ${ }^{4}$
Pendekatan belajar dapat diidentifikasi dengan menggunakan kuesioner pendekatan belajar. Salah satu kuesioner pendekatan belajar yang banyak dipakai adalah Study Process Questionnaire (SPQ) yang dikembangkan oleh Bigg. Kuesioner ini dapat menilai pendekatan belajar mendalam dan pendekatan belajar dangkal. ${ }^{1,5}$

Uji kompetensi merupakan penilaian kemampuan mahasiswa program pendidikan profesi dokter meliputi ranah kognitif, psikomotor dan afektif yang bersifat nasional bagi mahasiswa program profesi dokter dengan tujuan untuk:

1. Menjamin lulusan program profesi dokter yang kompeten dan terstandar secara nasional.

2. Menilai sikap, pengetahuan, dan keterampilan serta etika profesi dan disiplin keilmuan sebagai dasar untuk melakukan praktik kedokteran.

3. Memetakan mutu pendidikan di setiap institusi pendidikan kedokteran.

Memberikan umpan balik proses pendidikan pada fakultas kedokteran.

5. Mempersiapkan lulusan program profesi dokter dalam menghadapi Masyarakat Ekonomi ASEAN

Uji Kompetensi Mahasiswa Program Profesi Dokter (UKMPPD) menggunakan dua metode asesmen yang masing-masing metode bertujuan untuk menilai kompetensi yang berbeda. Metode yang pertama adalah ujian pilihan ganda dengan menggunakan uji berbasis computer (Computer Based Test/ $C B T$ ), tujuannya adalah penekanan terhadap 
penilaian pada ranah kognitif. Metode kedua adalah Objective Structure Clinical Examination (OSCE), tujuannya adalah penilaian pada ranah kognitif, psikomotor dan afektif. 6

\section{METODOLOGI PENELITIAN}

Penelitian ini merupakan penelitian deskriptif analitik dengan pendekatan crosssectional untuk mengetahui pengaruh pendekatan belajar dan kelulusan OSCE UKMPPD. Populasi adalah mahasiswa profesi dokter FKIK UNJA yang mengikuti OSCE UKMPPD periode Mei 2018 (25 orang) dan Agustus 2018 (34 orang) dengan jumlah total sebanyak 59 orang. Sampel adalah seluruh populasi (total sampling).

Variabel bebas penelitian ini adalah pendekatan belajar dan variabel terikat adalah kelulusan OSCE UKMMPD. Pendekatan belajar merupakan data skala kategorik dengan pembagian pendekatan mendalam dan pendekatan dangkal. Kelulusan OSCE UKMPPD merupakan skala kategorik lulus atau tidak lulus berdasarkan data resmi kelulusan UKMPPD yang dikeluarkan oleh panitia nasional UKMPPD

Metode pengambilan data yaitu data primer pendekatan belajar mahasiswa dengan menggunakan kuesioner "Revised Study Process Questionnaire 2 Factors (R-SPQ-F2) yang sudah divalidasi oleh Wijayanto tahun 2011. Kuesioner ini terdiri dari 20 pertanyaan untuk mengidentifikasi pendekatan belajar deep dan surface. Uji validitas dan reliabilitas yang dilakukan Wijayanto di-dapatkan korelasi positif > 0, 3 dan Chronbach Alpha > 0,6. Data kelulusan OSCE UKMPPD adalah data resmi kelulusan UKMPPD yang dikeluarkan oleh panitia nasional UKMPPD.

HASIL

Tabel 1. Distribusi frekuensi Pendekatan belajar mahasiswa peserta OSCE UKMPPD periode Mei $2018(\mathrm{~N}=25)$

\begin{tabular}{llcc}
\hline No & $\begin{array}{l}\text { Strategi } \\
\text { pembelajaran }\end{array}$ & Jumlah & Persentase \\
\hline 1. & $\begin{array}{l}\text { Pendekatan } \\
\text { mendalam }\end{array}$ & 14 & $56 \%$ \\
\hline 2. & $\begin{array}{l}\text { Pendekatan } \\
\text { dangkal }\end{array}$ & 11 & $44 \%$ \\
\hline & Jumlah & 25 & $100 \%$ \\
\hline
\end{tabular}

Pada tabel 1 terlihat bahwa sebagian besar pendekatan mahasiswa peserta OSCE UKMPPD periode Mei 2018 adalah pendekatan mendalam (56\%)

Tabel 2. Distribusi frekuensi Pendekatan belajar mahasiswa peserta OSCE UKMPPD periode Agutus 2018 ( $\mathrm{N}=34$ )

\begin{tabular}{llcc}
\hline No & $\begin{array}{l}\text { Strategi } \\
\text { pembelajaran }\end{array}$ & Jumlah & Persentase \\
\hline 1. & $\begin{array}{l}\text { Pendekatan } \\
\text { mendalam }\end{array}$ & 15 & $44,12 \%$ \\
\hline 2. & $\begin{array}{l}\text { Pendekatan } \\
\text { dangkal }\end{array}$ & 19 & $55,88 \%$ \\
\hline & Jumlah & 34 & $100 \%$
\end{tabular}

Pada tabel 2 terlihat bahwa sebagian besar pendekatan mahasiswa peserta OSCE UKMPPD periode Agustus 2018 adalah pendekatan dangkal $(55,88 \%)$. 
Tabel 3. Distribusi frekuensi Pendekatan belajar mahasiswa peserta OSCE UKMPPD gabungan ( periode Mei 2018 dan Agustus 2018) ( $N=59$ )

\begin{tabular}{llcc}
\hline No & $\begin{array}{l}\text { Strategi } \\
\text { pembelajaran }\end{array}$ & Jumlah & Persentase \\
\hline 1. & $\begin{array}{l}\text { Pendekatan } \\
\text { mendalam }\end{array}$ & 30 & $50,85 \%$ \\
\hline 2. & $\begin{array}{l}\text { Pendekatan } \\
\text { dangkal }\end{array}$ & 29 & $48,15 \%$ \\
\hline & jumlah & 59 & $100 \%$
\end{tabular}

Pada tabel 3 terlihat bahwa sebagian besar pendekatan mahasiswa peserta OSCE UKMPPD periode Agustus 2018 adalah pendekatan dalaml $(50,85 \%)$.

Tabel 4. Distribusi frekuensi kelulusan OSCE UKMPPD periode Mei $2018(\mathrm{~N}=25)$

\begin{tabular}{llll}
\hline No & Kelulusan & Jumlah & Persentase \\
\hline 1. & Lulus & 19 & $76 \%$ \\
\hline 2. & Tidak lulus & 6 & $24 \%$ \\
\hline & Jumlah & 25 & $100 \% 34$
\end{tabular}

Pada tabel 4 terlihat bahwa sebagian besar mahasiswa peserta OSCE UKMPPD periode Mei 2018 lulus (76\%)

Tabel 5. Distribusi frekuensi kelulusan OSCE UKMPPD periode Agustus 2018 ( $\mathrm{N}=34$ )

\begin{tabular}{clll}
\hline No & Kelulusan & Jumlah & Persentase \\
\hline 1. & Lulus & 26 & $76,47 \%$ \\
\hline 2. & Tidak lulus & 8 & $23,53 \%$ \\
\hline & Jumlah & 34 & $100 \%$
\end{tabular}

Pada tabel 5 terlihat bahwa sebagian besar mahasiswa peserta OSCE UKMPPD periode Agustus 2018 lulus (76,47\%)
Tabel 6. Distribusi frekuensi kelulusan OSCE UKMPPD gabungan (periode Mei 2018 dan Agustus 2018) $(\mathrm{N}=54)$

\begin{tabular}{llll}
\hline No & Kelulusan & Jumlah & Persentase \\
\hline 1. & Lulus & 45 & 76,27 \\
\hline 2. & Tidak lulus & 14 & 23,73 \\
\hline & Jumlah & 59 & $100 \%$
\end{tabular}

Pada tabel 6 terlihat bahwa sebagian besar mahasiswa peserta OSCE UKMPPD gabungan periode Mei 2018 dan Agustus 2018 lulus $(76,27 \%)$

Selanjutnya dilakukan analisis statistic menggunakan uji regresi untuk mengidentifikasi pengaruh pendekatan belajar terhadap kelulusan OSCE UKMPPD, berikut hasilnya

\begin{tabular}{|c|c|c|c|c|c|c|}
\hline \multicolumn{2}{|c|}{ Model } & $\begin{array}{c}\text { Sum } \\
\text { of } \\
\text { Squar } \\
\text { es }\end{array}$ & df & $\begin{array}{l}\text { Mean } \\
\text { Square }\end{array}$ & $F$ & Sig. \\
\hline 1 & $\begin{array}{l}\text { Reg } \\
\text { ress } \\
\text { ion }\end{array}$ & $\begin{array}{c}456,11 \\
4\end{array}$ & 2 & 228,057 & $\begin{array}{c}3,17 \\
7\end{array}$ &, $049^{b}$ \\
\hline & $\begin{array}{l}\text { Resi } \\
\text { dual }\end{array}$ & $\begin{array}{c}4020,4 \\
56\end{array}$ & $\begin{array}{l}5 \\
6\end{array}$ & 71,794 & & \\
\hline & $\begin{array}{c}\text { Tota } \\
1\end{array}$ & $\begin{array}{c}4476,5 \\
70\end{array}$ & $\begin{array}{l}5 \\
8\end{array}$ & & & \\
\hline
\end{tabular}

a. Dependent Variable: Nilai OSCE

b. Predictors: (Constant), Pendekatan Dangkal, Pendekatan Mendalam. 


\begin{tabular}{|c|c|c|c|c|c|c|}
\hline \multirow{2}{*}{\multicolumn{2}{|c|}{ Model }} & \multicolumn{2}{|c|}{$\begin{array}{l}\text { Unstandardi } \\
\text { zed } \\
\text { Coefficients }\end{array}$} & $\begin{array}{c}\text { Stan } \\
\text { dardi } \\
\text { zed }\end{array}$ & $t$ & Sig. \\
\hline & & B & $\begin{array}{l}\text { Std. } \\
\text { Error }\end{array}$ & Beta & & \\
\hline 1 & (Constant) & $\begin{array}{l}49,2 \\
43\end{array}$ & $\begin{array}{l}14,65 \\
1\end{array}$ & & 3,361 & 001 \\
\hline & $\begin{array}{l}\text { Pendekata } \\
\mathrm{n} \\
\text { Mendalam }\end{array}$ & ,266 & ,313 & ,115 & ,850 & ,399 \\
\hline & $\begin{array}{l}\text { Pendekata } \\
\text { n Dangkal }\end{array}$ & ,503 & 200 & ,340 & 2,520 & ,015 \\
\hline
\end{tabular}

a. Dependent Variable: Nilai OSCE

Berdasarkan uji statistic tersebut didapatkan nilai alpha $<0,05$, hal ini menunjukkan ada pengaruh yang bermakna antara pendekatan belajar dengan kelulusan OSCE UKMMPPD.

\section{PEMBAHASAN}

\begin{tabular}{lr}
\multicolumn{2}{c}{ Berdasarkan hasil penelitian } \\
didapatkan bahwa pendekatan belajar \\
mahasiswa peserta OSCE UKMMPD periode
\end{tabular}
Mei 2018 tebanyak adalah pendekatan mendalam (56\%) dengan tingkat kelulusan OSCE UKMPPD 76\%, sementara pendekatan belajar mahasiswa peserta OSCE UKMMPD periode Agustus 2018 tebanyak adalah pendekatan dangkal $(55,88 \%)$ dengan tingkat kelulusan OSCE UKMPPD 76,4\%, secara gabungan didapatkan pendekatan belajar mahasiswa peserta OSCE UKMMPD tebanyak adalah pendekatan mendalam (50,85\%) dengan tingkat kelulusan OSCE UKMPPD
Sig. 76,27\%. Data analisis statistic menunjukkan pengaruh yang bermakna antara pendekatan belajar dengan kelulusan OSCE UKMPPD

Berdasarkan hasil di atas dapat terlihat bahwa mahasiswa dengan pendekatan mendalam memiliki kemungkinan lulus lebih tinggi dibanding mahasiswa dengan pendekatan dangkal. Mahasiswa dengan pendekatan belajar mendalam (deep approach) lebih fokus pada pemahaman, mampu melakukan evaluasi terhadap materi pembelajaran, termotivasi, tertarik, mampu menghubungkan dengan pengetahuan sebelumnya, berpandangan luas dan menghubungkan dengan kenyataan yang terjadi di lapangan, sementara mahasiswa dengan pendekatan dangkal (surface approach) dicirikan dengan belajar hanya menghafal, hanya mengingat informasi, berpandangan sempit, motivasi karena takut gagal atau motivasi, ekstrinsik, tidak bisa membedakan konsep dasar dan contoh. 1,2

Namun, ada juga yang mengelompokan pendekatan belajar yang ketiga yaitu pendekatan belajar strategic (strategic approach) atau achieving approach. Pendekatan yang ketiga lebih berorientasi pada nilai tinggi. Mahasiswa kelompok ini pada saat persiapan ujian, mereka belajar dari kumpulan soal ujian yang lama, mengatur waktu dan strategi untuk mendapatkan hasil yang bagus dan hanya belajar materi yang akan dinilaii ${ }^{7,8}$

Pendekatan belajar bukan merupakan karakteristik mahasiswa tetapi tergantung dari konteks pembelajaran. Berdasarkan teori 
pendekatan belajar oleh Biggs, pendekatan belajar pada mahasiswa di pendidikan tinggi dipengaruhi oleh motivasi mahasiswa, keluarga, jenis kelamin, budaya, lingkungan belajar, kurikulum, self-efficacy. ${ }^{6}$ Penelitan Kek, Darmawan, Chen (2007) mendapatan bahwa faktor yang paling berpengaruh terhadap pendekatan belajar mahasiswa adalah lingkungan belajarendekatan belajar dapat berguna bagi institusi untuk pemberian materi pelajaran. ${ }^{9}$

Hubungan pendekatan belajar dan hasil belajar pada penelitian ini bermakna .Hal ini menunjukan bahwa mahasiswa yang belajar dengan pendekatan mendalam (deep approaches) lebih banyak yang berhasil dalam pencapaian hasil belajar. Hasil penelitian ini hampir sama dengan penelitian Tarabashkina \& Lietz (2011) yang menunjukan bahwa pendekatan belajar mendalam (deep approaches) dan strategic approaches berkontribusi tinggi dengan hasil belajar. Mahasiswa yang menggunakan deep approaches mempunyai hasil belajar yang lebih tinggi, mahasiswa Penelitian Lietz dan Tarabashkina (2009) juga mendapatkan bahwa pendekatan belajar mempunyai pengaruh terhadap hasil belajar mahasiswa, deep approach mempunyai prestasi dan performan yang lebih baik. ${ }^{10,11,12}$

Pendekatan belajar deep approach dapat membantu mahasiswa berhasil dalam ujian. Pada pendekatan deep mahasiswa belajar dengan sungguh-sungguh untuk memahami materi pelajaran, mampu mengaplikasikan materi yang dipelajari, memahami hal yang mendasar, tertarik dengan materi yang dipelajari, sehingga mereka akan bersungguh- sungguh dan belajar lebih keras. Tetapi mahasiswa yang belajar dengan strategic approaches lebih berhasil dalam ujian dikarenakan mahasiswa mampu mengatur waktu dan cara belajarBeradasarkan teori yang diusulkan oleh Biggs, bahwa pendekatan belajar ditentukan oleh motivasi yang mendorong mahasiswa untuk belajar dan menerapkan strategi belajar. Pada pendekatan deep approach, seseorang mempunyai keinginan belajar terhadap suatu materi dan diikuti oleh pendekatan strategi untuk berkompetisi. Pendekatan juga didasarkan pada proses infomasi yaitu surface hanya mengandalkan memori atau ingatan, deep approach fokus pada dasar dan proses pemahaman. ${ }^{1,13,14}$

\section{KESIMPULAN}

Pendekatan belajar mahasiswa berpengaruh positif pada kelulusan OSCE UKMMPD 


\section{DAFTAR PUSTAKA}

1. Lublin J. Deep surface and strategic approaches to learning. Center for teaching learning. Good practice in teaching and learning 2003: 1-11

2. Gadelrab HS. 2011. Factorial structure and predictive validity of approaches and study skill inventory for students (ASSIST) in Egypt: A confirmatory factor analysis approach.Electronic Journal of Research in Educational Physcology 2011; 9(25): 1197-1218

3. Wijayanto R. Hubungan antara persepsi pembelajaran dengan pendekatan belajar mahasiswa blok muskuloskletal di Fakultas kedokteran Universitas Pelita Harapan. Tesis Pasca Sarjana. Universitas Gadjah Mada, Indonesia, 2011.

4. Dasari B. Hongkong student approaches to learning: cross-cultural comnparison. US-China Education Review 2009; 6(12): 46-58

5. Penlington R, Joyce T, Tudor J, Thomson J. Do different learning conteks, processes and environment affect perceptions, dispositions and approaches to learning. The Higher Education Academy 2012: 1-6

6. Kek MA, Darmawan IGN, Chen YS. Family, learning environments, learning approaches and student outcomes in Malaysian private university. International Education Journal 2007; 8(2): 318-336.

7. Liew SC, Sidhu J, Barua A. The relationship between learning preference (style and approaches) and learning outcomes among pre-clinical undergraduate medical students. BMC Medical Education 2015; 15(44): 2-14. Lietz P, Tarabashkina L. The impact of values and learning approaches on achievement: Do gender and academic dicipline make a difference. Australian Association for Research in Education. Paper Presented at The AARE Annual Conference Canbera; Canbera, 2009; 1 - 19

8. Tarabashkina $L$, Lietz $L$. The impact of values and learning approaches on student achievement: gender and academic discipline influences. Issues in Educational Research 2011; 21(2): 210- 231.

9. Matthews B. An examination of changes in the approaches to learning of confucian herritage culture $(\mathrm{CHC})$ student's over time in a new social, cultural, and academic environment. Flinder University Institute of International Education, 2001

10. Rhem J. Deep/surface approaches to learning in higher education: A research update. Essays on Teaching Exellence 2009; 21(8): 1-5

11. Lietz $P$, Matthews $B$. Are values more important than learning approaches? Factor influencing student performance at an international university. 2007

12. Onen J. Connections between modes of thinking and learning approaches: implications for education and research. Journal of Education and learning 2015; 4(1): 84-96

13. Peter D, Peter J. Approaches to studying, academic achievement and autonomy, in higher education sport students. Journal of Hospitality, leisure, sport \& Tourism Education 2007; 6(2): 16-28.

14. Richardson JT. Students aproaches to learning and teachers' approaches to teaching in higher education. Educational Physchology 2005; 25(6): 673-680 